\title{
AUSGEWÄHLTE ASPEKTE DER ZUKUNFTSFÄHIGEN EHE- UND FAMILIENSPIRITUALITÄT ALS AUSDRUCKSFORM DER RETINITÄT DER GEISTLICHEN RESSOURCEN FÜR DIE GESELLSCHAFT
}

\section{Wybrane aspekty przygotowanej na przyszłość duchowości małżeństwa i rodziny jako forma wyrazu trwałości wartości duchowych dla społeczeństwa}

Artykut stanowi próbę ukazania ukierunkowanych na przyszłość teologicznych i sprawdzonych $w$ duszpasterstwie form duchowości matżeństwa i rodziny w sensie nowej ewangelizacji. Trwałość duchowych wartości chrześcijańskiego małżeństwa i rodziny opiera się na świadomie i aktywnie przeżywanej wspólnocie osób, która bardzo ubogaca społeczeństwo. Podstawę tej zorientowanej na przyszłość chrześcijańskiej duchowości stanowi osobista decyzja matżonków potwierdzona dobrowolnym sakramentalnym słowem „,tak”.

Słowa kluczowe: duchowość małżeństwa i rodziny, wartości duchowe, nowa ewangelizacja.

${ }^{1}$ Ks. Artur Żuk - pochodzi z Głogowa na Dolnym Śląsku, współpracownik Katedry Teologii Pastoralnej i Duchowości na Katolickim Uniwersytecie w Eichstätt-Ingolstadt w Bawarii, Niemcy. Specjalizując się w teologii dogmatycznej, zajął się pogłębieniem problematyki duchowości małżeństwa i rodziny. W swej habilitacji ukazał, iż prawdziwa, oparta o chrześcijańską naukę duchowość małżeństwa i rodziny, posiada swoje korzenie w aktywnie przeżywanej communio personarum małżonków i całej rodziny. Stanowi ona nie tylko bazę i zasoby dla samego małżeństwa i rodziny, ale poprzez nie także dla całego Kościoła i społeczeństwa. 
Die vorliegende Studie steht im Licht der Herausforderung eine im Sinne der Neuevangelisierung reflektierte Sicht der zukunftsfähigen theologieorientierten und pastoral fundierten Formen der Ehe- und Familienspiritualität zu erörtern. Diese angestrebte und erwartete Zukunftsfähigkeit soll sich vor allem im Bereich der Nachhaltigkeit (Retinität) der spirituellen Dimensionen und Werte der christlichen Ehe und Familie beweisen, die als Basis der bewusst und aktiv gelebten communio personarum in der ehelichen und familiären humanökologischen Umwelt gelten und zugleich wichtige Ressourcen für die Gesellschaft liefern.

Den Ausgangspunkt dieser zukunftsorientierten christlichen Spiritualität bildet die persönliche Entscheidung der Ehegatten, die mit dem freien $J a$-Wort besiegelt wird. Für die getauften Christen bekommt das $J a$-Wort der Treue dadurch sein besonderes Gewicht, dass sie es sich vor Gott und im Raum der kirchlichen Glaubensgemeinschaft versprechen. Ihre Liebe wird zum Sakrament der Nähe Gottes, das ihre gemeinsame Lebensgeschichte unter ein bleibendes Vorzeichen stellt. Ihr menschliches $J a$-Wort, das sie einander geben, ist von dem endgültigen $J a$, das Gott in Jesus Christus zu uns gesprochen hat, getragen und umfangen. Ihre Liebe ist im Sakrament der Ehe geheilt und geheiligt.

Das freie $J a$-Wort der Ehegatten, das sie nicht nur miteinander verbindet, sondern auch in die radikale Nachfolge Jesu Christi stellt, verlangt nach einer sicheren theologischen, spirituellen, evangelischen Verortung, die das Fundament für die Entscheidung der Ehegatten bildet, und eine neue Sicht des vertieften Ehelebens nach den Evangelischen Räten erschließt. Dadurch werden der Ehe und Familie eigene Lebensbereiche eröffnet, die im Rahmen einer authentischen Ehespiritualität ihre Vitalität und Lebbarkeit demonstrieren.

Die Untersuchung der bestehenden Ressourcen der Ehe- und Familienspiritualität als konkrete Möglichkeiten des Aufbaus und der humanen Entwicklung einer christlichen und weltlichen Gesellschaft steht im Mittelpunkt des vierten Kapitels. Die allgemeinen und besonders die christlichen Werte, die diese Ressourcen mit sich bringen, sollen zur Wandlung der ehelichen und familiären Entwicklungsprozesse (politisch-wirtschaftlich, kultur-geistlich, sozio-ökologisch) führen, wie auch zur Bildung einer im Sinne der christlichen Spiritualität erneuerten und humanisierten Gesellschaft beitragen. Es gilt zudem das Paradigma communio personarum als Grundlage der gesamten Zivilisation aufzuzeigen und die unverzichtbare Rolle der Ehe und Familie im Rahmen der modernen Gesellschaft wahrzunehmen, zu würdigen und zu konkretisieren. 


\section{Bausteine der zukunftsfähigen Ehespiritualität}

In der ersten Ausgabe des berühmten deutschen Lexikons für Theologie und Kirche aus dem Jahr 1937 findet man den Begriff „Spiritualität“" noch nicht, denn diese wurde mit ,Frömmigkeit“" identifiziert und als solche beschrieben ${ }^{2}$. Logischerweise findet sich auch der vertiefte und konkretisierte Begriff „Ehespiritualität“ nicht. Man definierte damals „Frömmigkeit“ als eine Gesinnung der Liebe und der Ehrfurcht gegenüber Gott, die sich in spezifischen religiös-kultischen Handlungen sowie in einer besonderen Haltung dem Geschaffenen, also der menschlichen Gemeinschaft, der eigenen Person und den Dingen gegenüber ausdrückt ${ }^{3}$. In der so definierten Haltung unterschied man dementsprechend zwischen Mystik und Askese, wobei man die Mystik eher als die persönliche Weise der Beziehung zu Gott verstand, die sich im Gebetsleben, in der Besinnung und im Empfang der Sakramente ausdrückte, und die Askese eher als religiösen Umgang zuallererst mit sich selbst, dann in der Gemeinschaft mit den Mitmenschen, wie auch mit der Umwelt ${ }^{4}$. Diese Formen der Frömmigkeit galten also allgemein für alle katholischen Christen und Christinnen. Allerdings ließ sich ein Unterschied beobachten. Es gab die Kleriker und Ordensleute, die sich intensiver und beinahe professionell diesen Formen widmeten und die verheirateten und unverheirateten Laien, die eher eine reduzierte Form des geistlichen Lebens praktizierten.

Dieser Kontext beweist, laut Thomas Knieps-Port le Roi, dass man eher von einer „Frömmigkeit in der Ehe“, als von einer „,ehelichen Frömmigkeit" sprechen $\mathrm{kann}^{5}$. Man hat zwar zwischen verschiedenen theologischen und klösterlichen Formen der Frömmigkeit unterscheiden können, doch für eine berufungsspezifische ,eheliche Frömmigkeit" findet man keine direkten Beweise, da die Eheleute als gewöhnliche Laien galten, die sich eben mit dem geistlichen Leben nicht so beschäftigen, wie die „Profis“" in den Kirchen und Klöstern ${ }^{6}$.

Erst die Ausbreitung des ziemlich ,jungen“ Begriffes Spiritualität hat neue Horizonte des geistlichen Lebens aufgetan, in denen das Monopol der „Profis“

2 C. Schütz, Christliche Spiritualität, in: Praktisches Lexikon der Spiritualität, Freiburg 1988, S. 1170; J. Subdrack, Gottes Geist ist konkret. Spiritualität im christlichen Kontext, Würzburg 1999, S. 36-40.

3 A. Auer, Frömmigkeit, LthK 4 (1960), S. 398-405.

4 T. Knieps-Port le Roi, Ehespiritualität - ein Paradigmenwechsel in der Geschichte christlicher Spiritualität?, „Geist und Leben” 78 (2005), S. 249.

5 Ebd., S. 250.

${ }^{6}$ Ebd. 
auch den Laien zugänglich gemacht wurde. Im XIX. Jahrhundert bürgerte sich in der französischen Theologie der Begriff spiritualité ein. Das deutsche Wort Spiritualität ist also eine direkte Übersetzung des französischen Terminus? Selbst dieser geringe Zeitabstand deutet einen wesentlichen Wandel des Verständnisses christlichen Glaubens und dessen Vollzugs im praktischen Leben der Kirche an. Die Gleichstellung der Berufungen, die allgemeine Berufung zur Heiligkeit, der kommunitäre Charakter der ekklesialen Gemeinschaft und die communio als Grundlage des spirituellen, ehelichen und familiären Lebens, sind hierbei bedeutende Beispiele. Diesen beinahe revolutionären Paradigmenwechsel haben die Konzilsväter in den Schriften des Zweiten Vatikanischen Konzils vollzogen und dadurch zahlreiche neue Horizonte des kirchlichen Denkens aufgeschlossen.

Die soeben erwähnte interpersonale Gemeinschaft der Ehe, die in der theologischen Prämisse communio personarum ihre besondere christliche Prägung bekommt, ist von spezifischen und komplizierten Lebensbereichen und Aufgaben geprägt, die in der christlichen Spiritualitätsgeschichte bislang kaum besondere Beachtung gefunden haben. Vielfach handelt es sich dabei sogar um Elemente der Lebensgestaltung, die eher als Prüfung oder gar als Hemmnis für das geistliche Leben betrachtet werden. Einige Komponenten werden hier angeführt, um sowohl den angedeuteten Paradigmenwechsel zu illustrieren, als auch einige Skizzen und Orientierungen einer zeitgemäßen sowie zukunftsweisenden Ehespiritualität sichtbar zu machen.

Die amerikanische Spiritualitätsforscherin Dina L. Villegas gab in einem ihrer Artikel einen wichtigen Impuls zur Entwicklung der gegenwärtigen, christlichen Spiritualität der Ehe und Familie: „Die herkömmlichen christlichen Spiritualitäten haben viele Pfade, das christliche Ideal zu leben, aufgezeigt, doch nur wenige haben sich in der reichen zweitausendjährigen Geschichte des Christentums auf die Ehe als einen exemplarischen Weg zu diesem Ziel konzentriert. In der Tat haben die meisten klassischen Spiritualitäten das ehelose Leben als den idealen Weg der Nachfolge Jesu hervorgehoben. Deshalb ist es höchst notwendig, Spiritualitäten in den Blick zu nehmen und zu entwickeln, die aufweisen, wie die Ehe ein exemplarischer Weg zur Nachahmung Jesu sein kann $^{\text {“68. }}$. Man müsste also zuallererst die ungerechte Meinung korrigieren, dass

7 B. Fraling, Überlegungen zum Begriff Spiritualität, in: Lasst euch vom Geist erfüllen! (Eph 5, 18), Beiträge zur Theologie der Spiritualität, Theologie der Spiritualität, Bd. 4, LIT Verlag 2001, S. 13.

8 D. L. Villegas, Marriage Spirituality. Living Out the Call to Be a Sign of God's Self-giving Love, „Intams” 7 (2001), S. 157. 
das Christentum nie eine Beziehung zur geistlichen Entfaltung des Miteinanders von Mann und Frau entwickelt habe.

In diesem zukunftsfähigen Kontext der Ehespiritualität drängt sich auch die Frage auf, was eigentlich den Unterschied zwischen einer sakramentalen Ehe und den vielfältigen heute praktizierbaren (heterosexuellen) Beziehungsformen ausmacht, die durchaus auch ethisch, verantwortlich und moralisch gelebt werden? Gerade auf diese Frage kann nur die Spiritualität der Ehe und Familie eine tragfähige Antwort geben. Es handelt sich selbstverständlich nicht um Spiritualität im Sinne konkreter Formen christlicher Frömmigkeit, sondern eher um eine „Grammatik der Lebensgeschichte, die dem Glaubensleben, der Beziehung zu Gott und den Menschen konkrete Gestalt verleiht"

Es wird sich dann logischerweise nicht mehr um die Probleme innerhalb der Ehe handeln, die in den vergangen Jahrzehnten das Forschungsobjekt gewesen sind (Verhütung, voreheliche Sexualität, Empfängnisregelung, und so weiter), sondern vielmehr gilt dann die Aufmerksamkeit der Ehe als einer christlich geprägten Lebensform mit ihren spezifischen Herausforderungen ${ }^{10}$. Deswegen geht es hier auch nicht um die Auslegung der Formen der Spiritualität in Ehe und Familie, nicht um den Wert des Gebetslebens von Ehepaaren, auch nicht um die praktischen Hilfestellungen zur Gestaltung des ehelichen Glaubensweges, sondern um ein Anliegen grundsätzlicherer (ontologischer) Art. Es wird nach der Ehe selbst, als Form christlicher Existenz, gefragt, um davon ausgehend, theologische Grundlinien für deren zukunftsfähige und konkrete Entfaltung zu skizzieren ${ }^{11}$.

Mit „Spiritualität der Ehe“ meint Gunter M. Prüller-Jagenteufel nicht etwa eine Laienspiritualität im Unterschied zur priesterlichen. Denn einerseits ist die Spiritualität von Priestern nicht notwendig zölibatär, wie uns die Ostkirchen zeigen, und andererseits leben zahlreiche Laien, gerade auch im pastoralen Beruf $^{12}$, ihre Spiritualität ehelos. Das Komplement zur Ehe ist also nicht die Weihe, sondern die „Ehelosigkeit um des Himmelreiches willen“. Daher wird die Ehe als Sakrament und Berufung, das heißt als christliche Lebensform im

9 B. Fraling, Überlegungen zum Begriff der Spiritualität, in: Vermittlung und Unmittelbarkeit. Beiträge zu einer existentialen Ethik. Freiburg 1994 (SThE 59), S. 38.

${ }^{10}$ L. S. Cahill, Marriage: Developments in Catholic Theology and Ethics, TS 64 (2003), S. 78-105.

${ }^{11}$ G. M. Prüller-Jagenteufel, Ehe als eschatologische Existenz. Spiritualität der Ehe in der Spannung von Immanenz und Transzendenz, „Geist und Leben“ 77, S. 261.

${ }^{12}$ E. Sgreccia, Per una pastorale della vita umana, Siena 2011, S. 5-30. 
Vollsinn des Wortes in den Blick genommen ${ }^{13}$. Man müsste dann fragen, ob und auf welche Weise die christliche Ehe eine Lebensform darstellt, in der der existentielle Glaubensakt, das heißt die Nachfolge Christi, in einem Leben der Gottes- und Nächstenliebe seinen Ort und seinen Ausdruck finden kann ${ }^{14}$. Daher muss von beiden Eheleuten eine unbedingte, persönliche, freie und kommunitäre Entscheidung zur bewussten Christusnachfolge in Ehe und Familie getroffen werden, damit dieser lebenslange Prozess der bewussten und aktiven Nachfolge Christi nicht nur auf der Ebene frommen Wünschens bleibt, sondern Realität des kommunitären Lebens wird.

\section{Das freie $\boldsymbol{J a}$-Wort als Ausgangspunkt der Ehespiritualität (nach Andreas Wollbold)}

Jede Paarbeziehung als Teil der menschlichen Welt besitzt auch ihre eigene Geschichte, die im konkreten Kontext ihren Sitz im Leben hat. Es gehören dazu sicher alle Lebensbereiche, Lebenssituationen, Entwicklungen, Brüche und Umweltbedingungen. Diese zwischenmenschlichen Beziehungen existieren nie unabhängig von der Welt, sondern werden von allen Lebensdimensionen, politischen Faktoren, kulturellen, ökonomischen und religiösen Kräften, aber auch von den verschiedenen Erziehungsmethoden, Sozialmodellen und Geschlechterstereotypen berührt und beeinflusst. Beide Seiten bringen auch persönliche Prägungen in die gemeinsame Beziehung, zu der die Beiden in der Liebe und aus freiem Entschluss ihr $J a$-Wort sagen.

In seinem, die Ehespiritualität behandelnden Artikel ${ }^{15}$, beweist Andreas Wollbold, dass es sich um das auf dem $J a$-Wort aufbauende eheliche Fundament handelt, welches im Rahmen der Liturgie der Eheschließung feierlich angelegt wird ${ }^{16}$. Das $J a$-Wort betrifft infolgedessen nicht nur das leib-seelische Erleben, sondern auch die gemeinsame Geschichte der Ehegatten. Die Formel „Vor Gottes Angesicht - als Bild Gottes ihm zugekehrt ${ }^{17}$ - nehme ich dich als

${ }^{13}$ M. Knapp, Die Ehe als christliche Lebensform. Überlegungen zur Ehespiritualität, „Geist und Leben”, Hft. 6, Nov./Dez. 2010, S. 433-444.

${ }^{14}$ G. M. Prüller-Jagenteufel, Ehe als eschatologische Existenz ..., op. cit., S.262.

${ }^{15}$ A. Wollbold, Fehlt eine Spiritualität der Ehe?, „Geist und Leben” 75 (2002), S. 183-192.

${ }^{16}$ Die Feier der Trauung. In den katholischen Bistümern des deutschen Sprachgebietes, Herder 1993, S. 40-44.

${ }^{17}$ Dieser Einschub dient dem Autor (A. Wollbold) als Bekräftigung der schöpferischen Ordnung der sakramentalen Handlung. 
meinen Mann/meine Frau..." ist das einander geschenkte $J a$-Wort, das alle äußeren Erwartungen und Umstände von innen her sakramental prägt und verändert. Das liturgische Eheversprechen, vor Zeugen der eigenen Umwelt ausgesprochen, durchdringt gemäß den Ausführungen Wollbolds alles Äußere und erneuert es dadurch. Es weist auf die spirituelle und dadurch reformierende wie auch verinnerlichende Kraft des $J a$-Wortes in der Ehe hin ${ }^{18}$. Ab diesem Moment existiert nicht nur eine soziologische Gemeinschaft der zwei vermählten Personen, sondern eine christliche Ehe mit allen ihren Dimensionen, Privilegien, Rechten und Pflichten.

Das christliche Verständnis des $J a$-Wortes aus freiem Entschluss wirkt „langfristig modernisierend“19. Es betont nachdrücklich den freien Konsens als ehestiftend - frei von allen familiären, beruflichen, ökonomischen und sonstigen Umständen, um die tiefere Dimension der ehelichen Liebe zu unterstreichen ${ }^{20}$. Ein solches Verständnis der Freiheitsbeziehung beruht dann tatsächlich auf dem persönlichen Konsens und nicht auf den Absichten Dritter oder sonstiger Lebensumstände. „Entscheidend für ein Ehepaar ist somit nicht, dass es die von außen angetragenen Aufgaben erfüllt, sondern dass alles Gelebte vom freien Ja zum Anderen durchwirkt ist. Dadurch entsteht überhaupt erst der Innenraum der Beziehung von Mann und Frau, in dem sich viel später die Ideale der Romantik entwickeln können“'21.

Erst in diesem bewusst gelebten Lebensraum der Ehe kann das persönliche Ja zueinander auch das persönliche und gemeinsame Ja zum gemeinsamen Ziel - dem Heil werden. Es handelt sich dabei um ein lebenslanges Verständnis des $J a$-Wortes: nicht etwa bloß um das Ja zu der jungen und schönen Person des Partners, sondern um ein $J a$-Wort zu der „Ganzheit“ des Ehepartners, die auch dessen Ziel- das Heil beinhaltet. Dabei handelt es sich also um einen authentischen und gemeinsam eingeschlagenen Weg der Ehegatten hinein in eine eindeutige Realität, die weder einen zeitlich begrenzten „Liebeszauber“ kennt, noch eine Hintertür nach dem Motto: „solange es geht“, „solange wir uns lieben“ oder „solange wir es miteinander aushalten“. Dies erst ermöglicht die echte, spirituelle Entwicklung der Ehepartner, der ganzen ehelichen Beziehung

\footnotetext{
${ }^{18}$ A. Wollbold, Fehlt eine Spiritualität der Ehe?, op. cit., S. 187.

${ }^{19}$ Ebd., S. 187-188.

${ }^{20}$ Ebd., S. 189.

${ }^{21}$ Ebd.
} 
und der Familie. Für die Ehepartner gilt insbesondere das Duc in altum! ${ }^{22}$, um ein liebender Mensch zu werden, der durch sein eigenes Leben dem Partner auf dem Weg zur Heiligkeit treu zur Seite steht und für dieses hohe Ziel sogar sein Leben zu opfern bereit ist.

Um die Schönheit der zukunftsfähigen Ehespiritualität zu betonen, die aus dem ernsthaft und bewusst gelebten $J a$-Wort der Ehegatten hervortritt, vermeidet es A. Wollbold nicht, die gegenwärtigen Schwierigkeiten anzusprechen: „Angesichts freier Partnerwahl und Individualisierung scheint dieses Vermächtnis der Tradition zukunftsweisend. Christlich Ehe zu leben heißt danach, ein freies, nüchternes, tapferes und vor allem liebendes Ja zum Anderen mitten in seiner und der eigenen Welt zu wagen. Aufgabe einer christlichen Paarspiritualität wäre es deshalb, eine hilfreiche, dem verantwortlichen Umgang mit den Umweltbedingungen angemessene Spiritualität zu entwickeln. Wandelbarkeit, sich auf veränderte Bedingungen einzulassen, etwa Schritt zu halten mit den Kindern, ihre Veränderung zu begleiten, sich dabei selber herausfordern zu lassen, später dann aber auch nach und nach die Kinder loszulassen und die Partnerschaft neu als Zweierbeziehung zu gestalten, all das gehört zu den wichtigsten Voraussetzungen einer gelingenden Verbindung. Christlich könnte es dabei näher hin sein, den Personkern nicht im Hin und Her der Lebensgeschichte treiben zu lassen, sondern ihn an Gott zu binden. Gerade weil der Mensch sich im letzten bei Gott angenommen weiß, kann er auch in Gelassenheit Handel und Wandel, Kommen und Gehen gestalten und, wo nötig, auch nur ertragen. So wird er bereit, in der Partnerschaft auch das Begrenzte, das ,So und nicht anders!" des anderen und seiner selbst zu bejahen. Ohne dieses Sich-Festmachen in Gott wird eine Partnerschaft immer dann besonders gefährdet sein, wenn sie an etwas Unabänderliches stößt, ohne es akzeptieren zu können. Damit stehen unsere Überlegungen bereits im dritten Element, dem Reifen zu einem liebenden Menschen im gemeinsamen Weg über Jahre hinweg“'23.

Die zukunftsfähige und Sinn stiftende christliche Ehespiritualität setzt also voraus, dass sich die Ehepartner einander im entschiedenen $J a$-Wort in ihrer Ganzheit annehmen. Dies beinhaltet die Vielfalt des Lebens und der Beziehung, sowie die als letztes Ziel verstandene Erfüllung der ehelichen Berufung, nämlich die Heiligkeit und das ewige Heil. Ein solches Verständnis von Spiri-

22 »Duc in altum!«, Dieses Wort erklingt heute für uns und lädt uns ein, dankbar der Vergangenheit zu gedenken, leidenschaftlich die Gegenwart zu leben und uns vertrauensvoll der Zukunft zu öffnen: »Jesus Christus ist derselbe gestern, heute und in Ewigkeit« (Hebr 13,8), in: Johannes Paul II., Novo Millennio Ineunte, Vatican 2001, 1.

${ }^{23}$ A. Wollbold, Fehlt eine Spiritualität der Ehe?, op. cit., S. 190. 
tualität in Ehe und Familie fördert einen großen Respekt vor dem Glauben des Ehepartners, stellt aber auch eine großzügige Unterstützung, Hilfe, liebende Mahnung und Belehrung dar, die dazu beiträgt, dass der gemeinsame eheliche und familiäre lebenslange Weg tatsächlich christlich verläuft und seine endgültige Vollendung findet.

Dank des ehelichen $J a$-Wortes kann ein gemeinsamer Weg eingeschlagen werden, auf dem die Paarbeziehung ihren Sinn nicht aus sich selbst, aus ihren eigenen Fähigkeiten und Begabungen, aus Leidenschaften oder der biologischen Funktion der Prokreation bezieht, „sondern nur und ausschließlich aus

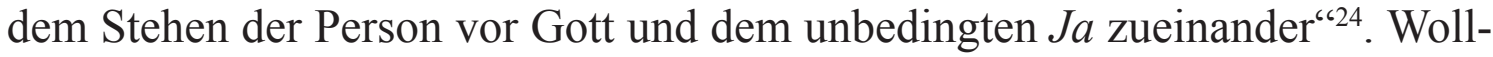
bold zählt in diesem Zusammenhang einige Faktoren der Ehespiritualität auf ${ }^{25}$, die zum Depositum der christlichen Spiritualität gehören:

- Die Bereitschaft, Verantwortung für sich und für das Leben zu übernehmen, ohne sich auf die vielfältigen Umstände der Gegenwart (z.B. political correctness) zu konzentrieren;

- Die Treue zur eigenen Berufung und das Bemühen, sie nach dem Willen Gottes zu erfüllen;

- Die Aufnahme- und Annahmebereitschaft für Anregungen und Impulse Gottes, für seine Gegenwart im persönlichen und gemeinschaftlichen Leben;

- Das Verständnis, dass Gott selbst das Entscheidende des Lebens in die Hand nehmen muss;

- Das Bewusstsein dafür, selbst stets der Umkehr zu bedürfen und eine Offenheit für die helfende Gnade Gottes behalten zu müssen;

- Das Bewusstsein für die Notwendigkeit, eine lebhafte, persönliche und kommunitäre Beziehung mit Gott führen zu müssen.

Die oben genannten Elemente der christlichen Spiritualität, die man selbstverständlich auch auf die Ehe und Familie überträgt, können zu einem Weg werden, auf dem die zwischenmenschliche Beziehung innerhalb der Ehe zu einer Beziehung der Eheleute mit Gott werden kann. In dieser Beziehung wachsen zuallererst die Partner miteinander in der Liebe, reifen in der gegenseitigen Verantwortung und bringen reiche Frucht dieser Liebe. Weil die Ehepartner das endgültige Ziel erreichen wollen, treten sie zunächst in eine Beziehung zu Gott. In anderen Worten ausgedrückt handelt es sich hier um die Erfüllung der allgemeinen christlichen Berufung - ein liebender Mensch zu werden, die Gottebenbildlichkeit in sich zu verwirklichen und die mystische

\footnotetext{
${ }^{24}$ Ebd.

${ }^{25}$ Ebd., S. 190-191.
} 
Vermählung (Vereinigung) mit Gott zu vollziehen. In Ehe und Familie gilt es, den gleichen Weg der Erfüllung der persönlichen christlichen Berufung auf den Weg der ehelichen und familiären Gemeinschaft zu übertragen ${ }^{26}$. Die christliche Ehe ermöglicht durch das $J a$-Wort der Partner einen Weg, miteinander liebende Menschen zu werden. Wollbold verstärkt dieses Verständnis, indem er den Weg der Ehegatten mit dem Weg Jesu Christi vergleicht: „Wie bei Christus ist das ein Weg nach unten, in die Passion [durchaus im Doppelsinn des Wortes! ]“227. Es geht ihm darum, dass „Menschen in der Unähnlichkeit mit Gott leben und dass deshalb eine Paarbeziehung immer eine Umkehrbeziehung ist. Auch Brüche und Durchbrüche aus Versteckspiel und Lüge zur Wahrheit gehören zu ihnen. Dass darum manches daneben geht und vieles viel besser sein könnte, ist keine Katastrophe, sondern der Normalfall, und glücklich, wer daraus den Mut schöpft, wenigstens in kleinen Schritten vorwärts zu kommen: Zwischen aller Sehnsucht nach heilem Leben und andererseits allem Erleben des Brüchigen und des Sündig-Gebrochenen, um uns und in uns aufzubrechen in das Land der Verheißung, das heißt, die Liebe des Dreifaltigen selbst abbilden zu dürfen. Das freilich ist eine gewaltige Aufgabe, die aller Unterstützung bedarf ${ }^{628}$.

Paare auf ihrem gemeinsamen spirituellen Weg sind herausgefordert zu lernen, mit ihren Unterschieden in ihren geistlichen Prozessen umzugehen, eine Balance $\mathrm{zu}$ finden zwischen der persönlichen und der gemeinsamen Gottesbeziehung und Formen der gemeinsamen Begegnung mit Gott und des geistlichen Austauschs zu finden ${ }^{29}$, die Respekt zeigen vor dem Eigen-Leben des Anderen, vor seinem Geheimnis mit Gott. Zu diesem Weg gehört auch, dass die Ehegatten spirituelle Krisen, Dürrezeiten (Erfahrung der Wüste), Zeiten der Gottentfremdung durchmachen - und das zu unterschiedlichen Zeiten. Der betroffene Ehepartner soll dann lernen, sich zuzumuten, eine gute Balance zwischen dem Nachgehen und dem Loslassen des Partners zu finden.

Wenn zur Qualität einer Paarbeziehung ihre spirituelle Verankerung in der transzendentalen Dimension gehört ${ }^{30}$, so ist doch die Ehespiritualität kein Instrument für Eheglück oder Ehegelingen. Ehen von Paaren, die einen spirituellen Weg gehen, sind keine besseren Ehen als andere, auch sie werden von

${ }^{26}$ S. Herzberg, Mystik der ehelichen Lebensform, „Geist und Leben”, Hft. 1, Jan./ März 2011, S. 42-49.

${ }^{27}$ Ebd., S. 192.

${ }^{28}$ Ebd.

${ }^{29}$ Der Prozess der Findung bedarf normalerweise der spirituellen Begleitung, Exerzitien, Seminare und des vertieften Gebetslebens.

${ }^{30}$ H. Jellouschek, Die Kunst als Paar zu leben, Stuttgart 1992. 
keiner Krise verschont. Wer Ehespiritualität instrumentalisiert, dem gilt das Verdikt Meister Eckeharts: „Ihr liebt Gott wie eine Kuh!“ (von der ihr Milch erwartet!) Ehespiritualität ist ein Weg, in der Ehe und als Glaubensgefährten zu lernen, Gott um seiner selbst willen zu lieben: „Gott allein genügt!“31

Diese schmerzliche und heilsame Relativierung der Ehe, welche die Ehe an ihren angemessenen Ort stellt, kann Paare von der Überforderung der ,Nachreligion der Liebe“ ${ }^{\text {32 }}$ befreien, einander Gott sein zu sollen, einander alles Glück der Erde und des Himmels bieten zu müssen. Diese Befreiung der Ehe als Fragment ${ }^{33}$ macht Paare frei, einander als begrenzte Menschen zu lieben und anzunehmen, ihre Unzulänglichkeiten mit göttlichem Humor zu ertragen und ihre Ehe als Vorgeschmack der Vollendung zu feiern ${ }^{34}$.

Wenn die Ehe- und Familienspiritualität die Ganzheit der Personen einschließen soll, dann muss in diesen Bereich auch die körperliche Dimension des Menschen mit hineingenommen werden. Ehepaare machen sich auf den Weg, ihren Leib und ihre Sexualität als gute Gabe Gottes zu sehen und anzunehmen. Sie versuchen, sich selbst und einander als „Tempel des Heiligen Geistes“ in Ehrfurcht und Freude zu begegnen und öffnen sich für die Ahnung, dass auch und gerade ihre Körperlichkeit und Sexualität zum Ort der Gottesbegegnung werden kann $^{35}$, was oft eher als Gegensatz zu Spiritualität gesehen wurde ${ }^{36}$. Umso mehr muss man in einer ernsthaften theologischen Reflexion über die Ehe- und Familienspiritualität die Dimension des Leibes und der Sexualität wahrnehmen. Diese Dimension darf man aber nicht von den anderen Lebensaufträgen (soziales Engagement, Apostolat) abkoppeln, sonst erlebt die Ehe- und Familienspiritualität nicht nur eine Verarmung, sondern sogar eine Verfälschung in ihrer Privatisierung. Um die gesamte Palette der Dimensionen der ehelichen und familiären Spiritualität im christlichen Sinne auf dem Weg der praktischen Umsetzung anzustreben, werden im nächsten Schritt der Forschung innovative Impulse und Rahmenbedingungen eines neukonzipierten, praktischen Projekts der spirituellen Begleitung vorgestellt. Als mögliche Zukunftsperspektive wird

${ }^{31}$ Teresa von Avila, Dzieła (dt.: Werke), Kraków 1987.

${ }^{32}$ U. Beck, Das ganz normale Chaos der Liebe, Frankfurt 1990, S. 231.

${ }^{33}$ H. Luther, Identität und Fragment, ,Theologia Practica” 20 (1985), S. 317-338.

${ }^{34}$ H. J. Weinz, Ehespiritualität - Der Sehnsucht einen Namen geben, „Lebendige Seelsorge" 1 (2001), S. 8-12.

${ }^{35}$ A. Grün, G. Riedl, Mystik und Eros, Münsterschwarzach 1993; P. Gyger, Mensch verbinde Himmel, Christliche Elemente einer kosmischen Spiritualität, Luzern/Stuttgart 1993.

${ }^{36}$ G. Bachl, Ganz oder halb? in: Der benedeite Engel, Freiburg 1987, S. 65-83; M. A. McPherson Oliver, Conjugal spirituality, „Spirituality Today” 43 (1991), S. 53-67. 
die Gründung einer neuen, kirchlichen Bewegung ins Visier genommen, in der sich die christlichen Ehen und Familien sammeln sollen, die auf bewusste und aktive Art und Weise ihre eigene christliche Spiritualität leben wollen ${ }^{37}$.

\section{Lebensentscheidung für die Nachfolge Christi (nach Gunter M. Prüll-Jagenteufel)}

In seinem Beitrag über die Ehe- und Familienspiritualität erörtert Gunter M. Prüller-Jagenteufel, inwiefern die Ehe eine konkrete Form der Nachfolge Christi darstellt und wie sich in der Spannung von Begrenztheit einerseits und sakramentaler Heilserfahrung andererseits, ihr spezifisch eschatologischer Charakter erweist ${ }^{38}$.

Er geht mit Lumen gentium ${ }^{39}$ von einer Berufung aller Christen zur Heiligkeit aus, die sich in jedem Stand konkretisieren kann. Der Autor beruft sich dabei auf Karl Rahners Entwurf einer Existentialethik ${ }^{40}$, der einen engen inneren Zusammenhang mit der moraltheologischen Lehre von der Fundamentaloption aufweist: Berufung versteht sich zunächst wesentlich als Ruf in die Nachfolge Christi, zu einem Leben aus der Gottesbeziehung, die sich in praktischer Nächstenliebe konkretisiert. Wie diese Konkretion im Einzelnen auszusehen hat, ist nun aber eine Frage der persönlichen Fähigkeiten und Optionen.

Hier komme, laut Prüller-Jagenteufel, die jeweils persönliche Lebensentscheidung des Menschen zur Geltung, auf welche Weise, in welchem Stand und in welchem Beruf sich diese Fundamentaloption wirksamer verwirklichen lässt. Es ist immer eine Sache geistlicher „Wahl“, die allerdings als Bewusstwerdung der persönlichen Berufung durchaus einen echten Verpflichtungscharakter aufweist. Unter diese sekundäre „Wahl“ fällt auch die Entscheidung, ob die Nachfolge Christi in der Ehe oder ehelos gelebt wird. Darüber hinaus ist es allerdings niemals nur eine Entscheidung „,zur Ehe“ an sich, sondern immer auch konkret zur Ehe mit einem bestimmten Menschen, die sich als der Ort erweisen soll an dem die Christus-Beziehung erfahren und die Nachfolge gelebt wird.

Dass Berufung in die Nachfolge wesentlich Berufung in den Dienst für andere ist, gilt dabei auch für die Ehe: Sie kann sich niemals selbst genügen,

${ }^{37}$ Diesem innovativen Spiritualitätsprojekt wird das Kapitel V. der vorliegenden Arbeit gewidmet.

${ }^{38}$ G. M. Prüller-Jagenteufel, Ehe als eschatologische Existenz ..., op. cit., S. 266.

${ }^{39}$ Lumen gentium 39-42.

${ }^{40} \mathrm{~K}$. Rahner, Über die Frage einer formalen Existentialethik, in: Schriften zur Theologie, Bd. 2, Einsiedeln 1955, S. 227-246; Erfahrung des Geistes und existentielle Entscheidung, in: Schriften zur Theologie, Bd. 12, Zürich 1975, S. 41-53. 
weshalb die „christlichen Eheleute“ gemäß ihrem Eheversprechen ihre Aufgaben nicht nur in „Ehe und Familie“, sondern ebenso „,in Kirche und Welt" zu erfüllen haben. Berufung ist also auch in der Ehe stets nicht nur persönliche und gemeinschaftliche, sondern immer auch ekklesiale und weltliche Berufung ${ }^{41}$. Gerade aufgrund dieses ekklesialen Charakters ist die Ehe zugleich ein Zeichen für die Welt. Wie die Kirche selbst wesentlich im Dienst an der Welt steht, so auch die Ehe. In ihrem Weltbezug können und sollen die Eheleute „Zeichen und Werkzeug “42 der göttlichen Liebe werden, die sie selbst empfangen haben und dann in die Welt hineintragen und fruchtbar machen sollen. An dieser Stelle erweist sich die während der Feier des Ehesakramentes erfolgte Befragung der Brautleute: „Sind Sie beide bereit, als christliche Eheleute Mitverantwortung in der Kirche und in der Welt zu übernehmen?"“43 als vollkommen berechtigt und im spirituellen Kontext durchaus zukunftsweisend.

Gemäß Prüller-Jagenteufel ist die Ehe demzufolge eine wesentlich konkretisierte, weltliche Gottesbeziehung ${ }^{44}$. Sie gründet im definitiven Ja Gottes zum Menschen und bildet somit einen Ort des „Esse in Christo“. Dies bedeutet nichts anderes, als dass den Ehepartnern von der Liebe Gottes her die Möglichkeit erwächst, die irdische Dimension (die Sünde) der Verfallenheit in sich selbst, also des eigenen Egos, im Hinblick auf die Gemeinschaft zu überwinden. Dieser Prozess ist nur dieser ehelichen Gemeinschaft möglich, die in der Gottesbeziehung verwurzelt ist und sich auf diesen Prozess hin öffnet. In diesem Sinne ist auch in der Ehe zunächst Gott „mit ungeteiltem Herzen“ zu lieben - auch Eheleute sind sich dessen bewusst, dass im Letzten nur Gott ihre Sehnsucht erfüllen kann. Die Liebe zum Ehepartner ist, von der Natur der Gottesbeziehung her, diesem semper maior zwar nicht untergeordnet, weil die wahre Liebe zu konkreten Menschen niemals in prinzipieller Konkurrenz zur Gottesliebe stehen kann, aber sie ist darin eingebettet ${ }^{45}$.

\section{Der eheliche Rätestand als qualifizierte Nachfolge}

Eine interessante Beobachtung nimmt Gunter M. Prüller-Jagenteufel vor, indem er einen engen Zusammenhang des Primates der Gottesliebe und der aus

${ }^{41}$ G. M. Prüller-Jagenteufel, Ehe als eschatologische Existenz..., op. cit., S. 266.

${ }^{42}$ Lumen gentium, 1.

${ }^{43}$ Die Feier der Trauung. In den katholischen Bistümern des deutschen Sprachraumes, Freiburg 1993, S. 38.

${ }^{44}$ G. M. Prüller-Jagenteufel, Ehe als eschatologische Existenz ..., op. cit., S. 268.

${ }^{45}$ Ebd. 
der Tradition stammenden evangelischen Räte feststellt. Seiner Meinung nach muss die Entfaltung der Gottesliebe in den evangelischen Räten sowie in der Spiritualität der Ehe einen großen Stellenwert innehaben und einen konkreten Platz beanspruchen. Die eheliche Keuschheit wird dabei selbstverständlich nicht als völlige sexuelle Enthaltsamkeit, die Armut nicht als totale Besitzlosigkeit und der Gehorsam nicht als unbedingte Unterordnung unter einen Oberen verstanden und gelebt. Dennoch stellen die Räte für Prüller-Jagenteufel unverzichtbare Grunddimensionen der zukunftsfähigen ehelichen Spiritualität dar ${ }^{46}$.

Wieder beruft sich der Autor auf die Werke von Karl Rahner ${ }^{47}$, der unter der Annahme einer Berufung jedes Christen zur Heiligkeit eine Verpflichtung jedes einzelnen Menschen zur radikalen und ungeteilten Liebe zu Gott und den Menschen sieht, wenn dieser in seinem Leben Christus wirklich nachfolgen will. Die konkrete Lebensform, in der diese Aufgabe realisiert wird, ergibt sich dann - wie oben bereits angedeutet - als je persönlich-existentielle Berufung. Rahner sieht in diesem Zusammenhang die wesentliche Bedeutung des Rätestandes in der prophetischen Zeichendimension: Der Rätestand verweise durch den Totalverzicht in einer Eindeutigkeit auf den Gottesbezug, die in der Ehe so nicht gegeben sei, weil diese stets im Weltbezug und damit in der Ambivalenz verbleibe ${ }^{48}$.

An dieser Stelle fragt Prüller-Jagenteufel, ob nicht auch der Rätestand insofern ambivalent sei, als er als Weltflucht missverstanden werden könnte, wodurch dann die inkarnatorische Wirklichkeit Gottes verschleiert würde. Eine gewisse Ambivalenz kommt somit beiden Lebensformen, der ehelichen wie der zölibatären, zu. Zudem sei im Unterschied zu Rahner festzuhalten, dass auch der Ehe eine nicht geringe prophetische Dimension zukomme, und zwar insbesondere im heutigen soziokulturellen Kontext, wo sie nicht mehr den „Normalfall“ darstellt: In ihrer Radikalität als freiwillige Bindung an einen Menschen ,in guten und in bösen Tagen, bis der Tod uns scheidet ${ }^{\star 49}$, verweist die Ehe über die bloße Immanenz hinaus auf Gott als den einzig tragenden Grund einer solchen Entscheidung. Zugleich bedeutet diese Bindung immer auch Verzicht und Selbstbeschränkung ${ }^{50}$.

${ }^{46}$ Ebd., S. 269.

${ }^{47}$ K. Rahner, Über die evangelischen Räte, in: Schriften zur Theologie, Bd. 7, Einsiedeln 1996, S. 412.

${ }^{48}$ Ebd., S. 428.

${ }^{49}$ Die Feier der Trauung. In den katholischen Bistümern des deutschen Sprachraumes, Freiburg 1993, S. 40.

${ }^{50}$ G. M. Prüller-Jagenteufel, Ehe als eschatologische Existenz ..., op. cit., S. 269. 
Die Fundierung der Ehe in der Gottesbeziehung erscheint also als unverzichtbar für die Entwicklung einer Skizze der Fundamente für die Spiritualität der Ehe und Familie. Es gilt also, diese Fundierung als Ausgangspunkt der Reflexion heranzuziehen, um anhand der evangelischen Räte einen breiteren Fokus entfalten zu können. Für die Erforschung der Ehespiritualität wäre eine genauere Insichtnahme der von Gunter M. Prüller-Jagenteufel vorgenommenen und wegen ihrer innovativen Sicht durch das Prisma der Ehe und Familie hervorstechenden Analyse der evangelischen Räte gewinnbringend. Die Ergebnisse seiner Forschungen wollen beweisen, dass für die Ehe nichts anderes gilt, als was für jede christliche Lebensform und Spiritualität in grundsätzlicher und wesentlicher Weise gilt. Die Ehe nämlich realisiere in ihrer existentiellen Ausrichtung hin auf Gott als dem letzten Grund des Seins den Primat der Gottesbeziehung. Von Gott her ist alles zu erwarten, seine Nähe wird gerade auch im und durch den Ehepartner erfahrbar ${ }^{51}$.

\section{Die eheliche Keuschheit}

Um ein eventuelles Missverständnis zu vermeiden und die eheliche Keuschheit richtig verstehen zu können, sollte angemerkt werden, dass man mit diesem Wort nicht nur die sexuelle Enthaltsamkeit meint, sondern sie aus einer positiveren Sicht der Sexualität heraus als deren personale Integration in das partnerschaftliche (Zusammen-) Leben versteht ${ }^{52}$. Keuschheit meint also nicht Tabus, sondern Integration. Nach Prüller-Jagenteufel, der sich auf William Kardinal Keeler beruft ${ }^{53}$, betrifft sie sowohl die emotionale wie auch spirituelle Ganzheit der menschlichen Person auf dem Gebiet der Sexualität.

Der Autor der mutigen Analyse beweist, dass die Keuschheit als Integration der eigenen Sexualität zunächst mit der Annahme der eigenen Sehnsüchte und Begrenzungen beginnt. Erst auf dieser Basis ist es möglich, die eigene Sexualität so zu kultivieren, dass eine herrschaftsfreie und ehrfürchtige personale Begegnung mit dem Partner möglich wird - eine Begegnung, die immer - auch in der Ehe - ein Moment des Verzichtes mit sich bringt, vor allem den Verzicht darauf, die eigenen Wünsche auf Kosten Anderer durchzusetzen.

Ausgehend von dieser Basis versteht sich Keuschheit als Ehrfurcht vor dem Anderen, was primär die Achtung des Partners als Person in seiner ab-

${ }^{51}$ Ebd., S. 273.

${ }^{52}$ L. Melina, Liebe auf katholisch. Ein Handbuch für heute, Augsburg 2009, S. 83-95.

${ }^{53}$ W. Keeler, Pastoral Statement: Marriage, Sexuality and Chastity, "Origin" 30 (2001), S. 521-524. 
soluten Eigenständigkeit meint. So verstandene Keuschheit bildet in der Ehe eine gewisse Kultur der erotischen Liebe, die nicht egozentrisch, sondern als Einander-Entsprechen und sich Einander-Schenken gelebt wird. Diese eheliche Kultur setzt eine Liebe ohne Nebenabsichten voraus, ohne eigensüchtige Motive, ohne Herrschaftsstreben - in Ausschließlichkeit und Treue.

Keuschheit versteht Prüller-Jagenteufel als Einander-im-Letzten-entzogen-Sein. Diese innovative Dimension wird insbesondere von der feministischen Theologie eingebracht, wenn sie Jungfräulichkeit wesentlich als Freiheit von Fremddefinitionen definiert. Maria, als Jungfrau, verwirklicht sich nicht durch ihren Mann, nicht durch ihren leiblichen Vater, sondern allein durch das Wirken Gottes; Selbststand und Gottesbeziehung stehen so jeder menschlichen Beziehung, - auch der ehelichen - voran. Das gilt gerade auch für die sexuelle Begegnung. Sie ist die Begegnung von eigenständigen und auf Gott bezogenen Menschen, die dem Partner gerade in ihrer wechselseitigen Hingabe im Letzten doch entzogen bleiben.

Es ergibt sich daraus eine besondere Ehrfurcht vor den Anderen, die die Tugend der Keuschheit ${ }^{54}$ der zölibatären wie der verheirateten Menschen konstituiert und die grundsätzlich allen Menschen gilt, ob man ihnen nun in sexueller Begegnung gegenüber tritt oder in jeder anderen ${ }^{55}$. Dies betrifft in ähnlichem Sinne auch die spirituellen Eigenschaften der anderen evangelischen Räte, weshalb die folgende Reflexion über Armut und Gehorsam vorgenommen wird.

\section{Die eheliche Armut}

Bei der ehelichen Armut handelt es sich keineswegs um eine dem evangelischen Rat der Armut gleichkommende Besitzlosigkeit. Den Kern des Verständnisses der ehelichen Armut bildet vielmehr die besondere spirituelle Praxis der freien Zurückweisung von Gütern. Die gilt nicht nur für kinderreiche Familien, die im Übrigen eine in der EU signifikant große Armutsgefährdung aufweisen $^{56}$, sondern auch für alle Eheleute, die dem gemeinsamen Lebensprojekt Vorrang vor dem jeweils eigenen einräumen. In Abgrenzung zu den konsumistischen Plausibilitäten der Gegenwart und der Einschränkung der persönlichen Verfügungsmacht über den eigenen Besitz, entfaltet Prüll-Jagenteufel vier Dimensionen der Kultur der evangelischen Armut in der Ehe.

${ }^{54}$ L. Melina, Liebe auf katholisch. Ein Handbuch für heute, Augsburg 2009, S. 150-154.

${ }^{55}$ G. M. Prüller-Jagenteufel, Ehe als eschatologische Existenz ..., op. cit., S. 272-273.

${ }^{56}$ Sozioökonomische Forschungsstelle, in: Familienbericht 2009, Armut und Armutsbedrohung, August 2009: www.salzburger-armutskonferenz.at 
Am wichtigsten scheint ihm das Loslassen vom irdischen Besitz zu sein. Die Lebenskultur der Ehe als Liebe wird auf dem Fundament des Seins und nicht des Habens aufgebaut. Diese Art der Armut befähigt die Ehepartner zur Gemeinschaft, die nur in einer Kultur des Teilens und der Solidarität entstehen kann. Diese persönliche und beinahe intime Solidarität gilt als Auftrag $\mathrm{zu}$ verstehen, der in „Kirche und Welt“ zu erfüllen ist und den wesentlichen spirituellen Herausforderungen der Ehe zugehört.

Die zweite Dimension der ehelichen Armut betrifft das Loslassen von vorletzten Sicherheiten. Prüll-Jagenteufel erklärt, dass die evangelische Armut eine Armut des Weges ist, um immer wieder loszulassen und neu aufzubrechen. Das betrifft nicht nur materielle Sicherheiten, sondern auch ideelle. Die Priorität ist doch das Wohlergehen des Ehepartners, daher sollte man alles, woran man sein Herz klammert, wonach man süchtig werden kann, radikal loslassen. Die spirituelle Herausforderung für die Ehepartner besteht hierbei darin, zu erkennen, dass sie nicht schon im gelobten Land angekommen sind, sondern vielmehr in einer Exodus-Gemeinschaft stehen, die noch auf dem Weg ist. Ehe spirituell zu leben bedeutet dann, sich auf einen offenen Prozess einzulassen, der immer wieder ungeahnte Herausforderungen mit sich bringt und neue Schritte der Entwicklung einfordert - sowohl vom Einzelnen als auch vom Paar gemeinsam.

Armut als Loslassen des Anderen ist wohl eine der wesentlichsten und schmerzhaftesten Herausforderungen für die Ehe. Nur wenn ich den Partner nicht besitzen will, wenn ich mich auch von meiner Beziehungssucht löse, ist personale Begegnung in Freiheit möglich.

Armut als Loslassen von sich selbst sieht Prüll-Jagenteufel als die letzte Konsequenz. Die Ehe ist auch ein „Übungsfeld“, sich selbst frei zu machen von den eigenen ungeordneten Anhänglichkeiten, um so offen zu werden für den Anderen, der mich beansprucht - und damit für Gott als den ganz Anderen, das absolute $\mathrm{Du}^{57}$.

\section{Der eheliche Gehorsam}

Wohl die größte Kontroverse in der gegenwärtigen voll individualisierten Welt und Gesellschaft ruft der Begriff des Gehorsams hervor. Im Zusammenhang mit der Ehe sei zunächst festgehalten, dass es dabei keineswegs um autoritär-patriarchale Rollenmuster geht. Vielmehr gilt auf dem Weg der Nachfolge für Prüll-Jagenteufel der erste Gehorsam stets und ausschließlich dem Willen Gottes, der sich in der Welt auf verschiedene Weise und unterschiedlich offen-

${ }^{57}$ Ebd., S. 270-271. 
bart. Er lehnt den ehelichen Gehorsam direkt an die lebhafte Beziehung der Ehepartner mit Gott an, die sich zuallererst im grundlegenden und einfachen Hinhören auf Gott realisiert.

Gehorsam als eheliches Fragen nach dem Willen Gottes: Für Prüll-Jagenteufel ist es durchaus wichtig, eine Kultur der Unterscheidung der Geister zu lernen, zu pflegen und zu vertiefen, die sowohl eine persönliche als auch eine gemeinsame Qualität des ehelichen und familiären Lebens darstellt. Jeder Ehepartner soll dann immer neu nach dem Willen Gottes für sich selbst fragen, aber ebenso beide gemeinsam nach dem Willen Gottes für sich als Paar, als Eltern, als Familie. Die für den Autor und die Eheleute entscheidende Frage lautet dann: „Wie kann ich, wie können wir gemeinsam Christus besser nachfolgen?“ Selbst diese Frage eröffnet den Ehegatten neue Horizonte und bildet ein festes Fundament ihrer Spiritualität.

Der Autor bezeichnet die Selbstannahme als wichtige Dimension des ehelichen Gehorsams. Das oben genannte gehorsame Auf-Gott-Hören sei nur auf der Basis einer grundlegenden Selbstannahme möglich. Gott spreche immer ein konkretes Menschsein an, und zwar durch die Menschen um die Ehepartner herum, an denen sie das Für-andere-Dasein verwirklichen können. Die Eheleute sind also zuallererst für sich die Verkünder Gottes, dann selbstverständlich für die eigenen Kinder, für die ganze Familie und für die ganze soziale Umwelt in der sie leben.

Gehorsam als Aufeinander-Hören: Diese typisch benediktinische Dimension des Gehorsams erklärt Anselm Grün, den Prüll-Jagenteufel in seinem Artikel zitiert und damit die besondere Bereitschaft meint, „sich auf die Gemeinschaft einzulassen, seine eigenen Bedürfnisse nicht zu verabsolutieren“ und im gemeinsamen Hinhören auf Gott zu erfahren, „wie wir konkret eine Antwort geben könnten auf die Zeichen unserer Zeit“58.

Dieser herausforderndste evangelische Rat wird in der Ehe an unterschiedlichen neuralgischen Punkten sehr konkret. Er betrifft besonders die Entscheidung über die Kinderzahl, das Berufs- und Lebensumfeld, über Beziehungen zu Herkunftsfamilien, Freundeskreisen und so weiter. Der Autor führt dazu Folgendes aus: „Grundsätzlich zeigt sich in einer solchen gemeinsamen Entscheidungsfindung aus dem Glauben die Grundhaltung eines dialogisch gelebten, diskreten Gehorsams, der zwar nicht in der Unterordnung unter einen Oberen besteht, wohl aber im Verzicht auf Selbstdurchsetzung und in gegenseitiger

${ }^{58}$ A. Grün, Und alles lassen, weil Er mich nicht lässt. Lebenskultur aus dem Evangelium, Freiburg 1995, S. 62. 
Unterordnung, die es erst möglich macht, sich dem Anliegen des Partners zu öffnen" ${ }^{659}$.

Diese durchaus interessante und für die christliche Ehespiritualität bedeutende Reflexion von G. M. Prüller-Jagenteufel über die evangelischen Räte in der Ehe und Familie bringt noch eine wichtige Prämisse zum Ausdruck, und zwar die, dass die Ehe keinesfalls als christliche Lebensform „der zweiten Klasse“ der zölibatären Lebensform des Rätestandes untergeordnet wird. Beide Formen realisieren christliche Existenz und beide sind dem entsprechend im Vollsinn des Wortes als Berufung zu bewerten und zu qualifizieren. Christlich gelebte Ehe erscheint dann, besonders in der heutigen Gesellschaft, ,als Gegenbild zum aktuellen neoliberalen Konzept der rücksichtslosen Gewinnmaximierung bei geringstmöglichem Aufwand (Armut); sie zeigt gegen die nichthinterfragte Plausibilität individualistischer Selbstverwirklichung die fundamentale Bedeutung der Gemeinschaft und des Miteinanders auf (Gehorsam); und sie setzt an die Stelle des ichbezogenen, möglichst verantwortungsfreien Auslebens der „eigenen“ Sexualität, die ein Leben lang partnerschaftlich zu gestaltende Kultur erotischer Beziehung (Keuschheit) ${ }^{\star 60}$.

Erst unter Berücksichtigung der spirituellen Dimensionen der evangelischen Räte, also in Keuschheit, Armut und Gehorsam, im mutigen und durchaus realistischen, durch die gegenseitige Liebe durchdrungenen Loslassen des Eigenen, im gemeinsamen Streben auf Gottes Verheißung hin, bewährt sich das freie $J a$-Wort der Eheleute. Dank diesen spirituellen Faktoren konkretisiert sich das $J a$-Wort und wird auch erst dann rational ${ }^{61}$.

Diese theologische Reflexion könnte der Entwicklung eines Modells oder eines theologischen Vor-Bildes dienen, ohne dabei zu moralisieren, und doch im vollen Wissen um die reale Möglichkeit der Realisierung der christlichen Ideale unter Berücksichtigung jeglicher Probleme, Schwächen, Begrenztheiten und Brüchigkeiten. Daher bedarf die Reflexion einer Ergänzung und Vertiefung, um die konkreten Räume, Konturen und Rahmenbedingungen der Verwirklichung der evangelischen Räte in der Ehe und Familie aufzuzeigen.

${ }^{59}$ G. M. Prüller-Jagenteufel, Ehe als eschatologische Existenz..., op. cit., S. 271.

${ }^{60}$ Ebd., S. 273.

${ }^{61}$ A. Wollbold, Fehlt eine Spiritualität der Ehe?, op. cit., S. 183-192; R. Miggelbrink, Ist die Ehe ein Sakrament?, „Geist und Leben” 74 (2001), S. 193-209. 


\section{Spezifische Lebensbereiche im Dienst der zukunftsweisenden Ehespiritualität (nach Thomas Knieps-Port le Roi)}

Das Leben jedes Menschen, aber auch der Gemeinschaften, die von der Mehrzahl der Menschen gebildet wird, also auch die ehelichen Gemeinschaften, sind gegenwärtig von verschiedenen komplizierten und herausfordernden Lebensumständen und Lebensbereichen geprägt. Diese wurden bislang in der Geschichte der Ehe- und Familientheologie, besonders der Spiritualität, eher als Hemmnisse oder zumindest als Lebensprüfungen betrachtet. Um eine gewisse Wende in diesem Bereich der Spiritualität von Ehe und Familie vollziehen zu können, müsste man eine neue Betrachtung der Elemente der Lebensgestaltung vornehmen, die den nachkonziliaren Paradigmenwechsel verdeutlichten und ein Bild der zeitgemäßen und zukunftsweisenden Ehespiritualität gäben. Einen gelungenen Versuch der Zeichnung solcher zukunftsfähigen Konturen der Spiritualität der Ehe und Familie findet man bei Thomas Knieps-Port le Roi, der die oben genannten Lebensbereiche in drei Komponenten ordnet ${ }^{62}$.

\section{Abgeschiedenheit in der ehelichen Beziehung}

Knieps-Port le Roi führt eine Vergleichsanalyse der verschiedenen Lebensformen der Abgeschiedenheit durch. Es handelt sich dabei um die Einsamkeit der Eremiten, wie auch um die gemeinschaftliche Einsamkeit der Mönche. In beiden Formen geht es um die „Gottsuche und die Christusnachfolge der Einzelperson in Form und Unterordnung des eigenen Ichs unter das göttliche Gebot. Das eine Mal geschieht das durch Entbehrung und Askese, wie sie das Einsiedlerleben abverlangt, das andere Mal durch den Gehorsam gegenüber dem Abt und den brüderlichen Umgang miteinander. Niemals aber ist auch im Gemeinschaftsleben des Mönchs die zwischenmenschliche Beziehung als solche von besonderer spiritueller Relevanz ${ }^{\text {“633 }}$.

Selbst auf Grund dieser kargen Überlegung müsste man in der ehelichen Spiritualität einen anderen Stellenwert der Einsamkeit und Gemeinschaftlichkeit erörtern. In Ehe und Familie soll keineswegs ein monastischer Lebensstill übernommen werden, in dem man etwa eine gewisse Flucht aus der mitmenschlichen Beziehungskultur übte. Vielmehr würde es sich um eine paarbezogene Spiritualität handeln, in der eine christliche Glaubenserfahrung stattfände, die für beide Ehepartner bedeutsam wäre und die einen konkreten, spirituellen Einfluss auf ihre Beziehung hätte. Selbst die Sehnsucht und das

${ }^{62}$ K. Knieps-Port le Roi, Ehespiritualität..., op. cit., S. 255.

${ }^{63}$ Ebd., S. 256. 
Verlangen nach Gemeinschaft und Beieinandersein impliziert den Archetyp der ersten kommunikativen Beziehung und Gemeinschaft, die zwischen den Drei Göttlichen Personen stattfindet. Im Rückgriff auf die Aussagen von R. Gaillardetz und M. Scharer ${ }^{64}$ stellt Knieps-Port le Roi konkret die Frage, ob nicht die Selbstmitteilung Gottes an die Menschen, die in der Person Jesu Christi gipfelt, ins menschliche Beziehungsleben hineinspiele und ob die Liebeskultivierung nicht den Zentralpunkt der christlichen Spiritualität, besonders der Ehe- und Familienspiritualität ausmache? Es würde sich selbstverständlich um die Kultivierung der Liebe Gottes handeln, sowohl bei den zölibatär Lebenden, wie auch in der ehelichen Beziehung, was noch einmal den Wert beider Stände auf den gemeinsamen Nenner bringt.

\section{Sexuelle Lebensgemeinschaft und Ehelosigkeit}

Die neue Sicht der Ehespiritualität, die das Zweite Vatikanische Konzil in der katholischen Theologie hervorgebracht hat, bestätigt sich vollkommen. Der Mitarbeiter des Konzils und spätere Papst Johannes Paul II. betonte stets mit Nachdruck, dass gerade die selbsthingebende Liebe der Ehepartner das Fundament ihrer Beziehung zueinander und zu Gott ist. Die von Gott stammende und sich in der Ehe und Familie verwirklichende bräutliche Liebe muss ihre Ganzheit in besonderer Weise auch in der sexuellen Gemeinschaft als Krönung der spirituellen Dimension der Liebe der Ehepartner zum Ausdruck bringen ${ }^{65}$.

In der Berufung auf die Dokumente des Lehramtes ${ }^{66}$ zeigt Knieps-Port le Roi den engen Zusammenhang zwischen der ehelichen Sexualität und dem ehelosen Leben; er beweist, wie diese beiden Lebensformen sich ergänzen und sogar voneinander abhängen. Dazu zitiert ${ }^{67}$ er den Kirchenvater Johannes Chrysostomos († 407): „Wer die Ehe abwertet, schmälert auch den Glanz der Jungfräulichkeit; wer sie hingegen preist, hebt deren Bewunderungswürdigkeit mehr hervor und macht sie leuchtender. Was nämlich nur durch den Vergleich mit Schlechterem gut erscheint, dürfte kaum besonders gut sein; was jedoch, verglichen mit anerkannt Gutem, noch besser ist, das ist im Übermaß gut ${ }^{“ 688}$.

${ }^{64}$ Ebd., S. 257.

${ }^{65}$ Johannes Paul II., Mann und Frau schuf er sie. Grundfragen menschlicher Sexualität, München 1981.

${ }^{66}$ Familiaris consortio 16; Katechismus der Katholischen Kirche 1620.

${ }^{67}$ K. Knieps-Port le Roi, Ehespiritualität..., op. cit., S. 258.

${ }^{68}$ Johannes Chrysostomos, De Virginitate X, c. 1 (PG 48, 540). 
Die theologische Reflexion wagt auch zu sagen, dass die Sexualität und der Eros zur leiblichen und seelischen Grundlage der ehelichen Beziehung gehören und darin ihren unveräußerlichen Platz haben. Knieps-Port le Roi bemerkt aber auch, dass das Christentum ziemlich viel Zeit dafür verwandt hat, die destruktiven und gottwidrigen Mächte zu benennen und zu brandmarken, die sich der Sexualität bemächtigen können. „Es ist darin in gewisser Weise dem Alten Testament gefolgt, das im Unterschied zu seiner religiösen Umwelt eine Sakralisierung und Mythisierung des Geschlechtlichen zurückgewiesen und einer Verquickung mit dem Göttlichen vorgebeugt hat. Darüber ist ein anderer Aspekt des biblischen Zeugnisses vernachlässigt worden, der in der Geschlechtlichkeit eine Gabe Gottes sieht, die - so jedenfalls legt es der zweite Schöpfungsbericht ${ }^{69}$ nahe - den Menschen beziehungsfähig und damit erst zum Menschen macht. Es bleibt zu hoffen, dass eine Spiritualität der Paarbeziehung dem Christentum dazu verhelfen kann, ein nüchternes, aber grundsätzlich positives Verhältnis zur Sexualität zu finden“"70.

\section{Sonderbezirke des religiösen ehelichen Lebens}

Mit den Sonderbezirken des spirituellen Lebens verbindet die christliche Spiritualität normalerweise besondere Orte der Gottesbegegnung, wie etwa Kirche, Kapelle, Kloster, Wallfahrtsort oder Exerzitienhaus. Weitet man den Fokus dieses Verständnisses und ersetzt man den Begriff „Bezirk“ durch „Raum“, wird man schnell auch auf die spezifischen und extra gewählten Gebetszeiten, religiösen Symbole, Bilder und Musik, liturgische Feiern und Bibelbetrachtungen aufmerksam ${ }^{71}$. Gerade diese strenge Aufteilung und Abgrenzung der profanen Räume von den spirituellen in der Ehe oder Familie scheint beinahe unmöglich. Nach Meinung Knieps-Port le Roi führten diese Schwierigkeiten bei den Theologen ${ }^{72}$ zur Bildung, Entwicklung und Einführung des Begriffs der „Alltagsspiritualität“ in den theologisch-spirituellen Sprachgebrauch. Dieser für die Ehe- und Familienspiritualität bestimmte Schlüsselbegriff beinhaltet eine Reihe von Lebenserfahrungen und Lebensbereichen, in denen der einzel-

${ }^{69}$ Gen 2, 4b-25.

${ }^{70}$ K. Knieps-Port le Roi, Ehespiritualität..., op. cit., S. 258; Die Problematik der Relativierung der Sexualität in der theologischen Reflexion über Ehe findet man im Artikel von A. Wollbold, Fehlt eine Spiritualität der Ehe?, op. cit., S. 183-192.

${ }^{71}$ K. Waaijman, Spiritualiteit. Vormen, grondslagen, methoden, Gent - Kampen 2000, S. 13-19.

${ }^{72}$ K. Knieps-Port le Roi, Ehespiritualität..., op. cit., S. 259. 
ne Mensch, wie auch das Ehepaar und die Familie, ihr Leben organisieren, ihre Entscheidungen treffen und ihre Beziehung zur Arbeits- und Berufswelt gestalten. Insbesondere beinhaltet dieser Schlüsselbegriff den Umgang und die Begegnung der Menschen mit ihren Mitmenschen und im Speziellen mit ihrem Ehepartner. Es handelt sich dabei um eine echte christliche und alltägliche Lebensführung, um ein für die christliche Spiritualität gewöhnliches Programm der täglichen Gottessuche. Diese Reflexion zeigt, wie wichtig eine "Ganzheitlichkeit" des ehelichen Lebens ist. Man sollte zugunsten der besseren Wahrnehmung des gemeinsamen ehelichen Lebenswerkes auf eine sterile und künstliche Aufteilung und Ausdifferenzierung der verschiedenen Lebensbereiche verzichten. Eine moderne und zukunftsfähige Ehespiritualität sollte eher Brücken zu den abgespaltenen Lebensbereichen aufbauen, um der Sehnsucht nach einer dem Leben und der Realität des Beziehungsalltags sinngebenden Beziehung gerecht werden zu können ${ }^{73}$.

\section{Rahmen der authentischen christlichen Ehespiritualität}

Damit die christliche Ehe- und Familienspiritualität nicht eine bloße Nachahmung oder sogar erzwungene Anpassung der ehelichen Lebensräume an eine herkömmliche monastische Spiritualität darstellt, muss man Rahmenbedingungen benennen, innerhalb derer sich die Forschung der Spiritualität wie auch konkrete Hinweise der Entwicklung einer authentischen Ehe- und Familienspiritualität bewegen könnten. Der bereits zitierte Autor - Thomas Knieps-Port le Roi will in einer „Ganzheitlichkeit“ des ehelichen und familiären Lebens mindestens drei solche Rahmenbereiche ausdifferenzieren, auf die eine ernsthafte Spiritualitätsforschung nicht verzichten darf. $\mathrm{Zu}$ diesen Bereichen zählt er die Bereiche der Lebenserfahrung, der Kirchlichkeit und der „Andacht" im Lebensalltag der Ehepartner ${ }^{74}$.

\section{Die eheliche Erfahrung}

Im Gegensatz zum Erfahrungsfeld der Mönche, Kleriker und Menschen, die gelobte Ehelosigkeit leben und ausüben (Virgo consecrata), bildet der den verheirateten Personen vorbehaltene spezifische Erfahrungsbereich den Boden der Ehe- und Familienspiritualität. Es handelt sich dabei um eine reiche Vielfalt der konkreten Lebensvollzüge, um den einfachen und alltäglichen Umgang mi-

\footnotetext{
${ }^{73}$ Ebd., S. 259-260.

${ }^{74}$ Ebd., S. 260-262.
} 
teinander, um die besonderen Momente intimer Zweisamkeit, aber auch um die höhere Form der gemeinsamen Gestaltung des bewussten, spirituell geprägten Lebensweges. Das Besondere an dieser Rahmenbedingung ist, dass sie keiner Neuentdeckung bedarf, sondern allenfalls einer bewussten und gemeinsamen Neubelebung, da die Spiritualitätsbasis in jeder ehelichen Beziehung gegeben ist. Knieps-Port le Roi fragt in diesem Kontext nur nach dem Modus ${ }^{75}$, wie die Ehepartner diesen durchaus natürlichen Erfahrungsraum erschließen können, sodass er für ihr geistliches Leben und für den gemeinsamen Glaubensvollzug relevant wird. Die Antwort bedarf einer eigenen Untersuchung, um den zusätzlich auftretenden Fragen nachgehen zu können: wie kann der Geist, der alles im Leben verwandelt, im Eheleben entdeckt werden? Inwieweit lassen sich die Ehepartner zu begeisterten Zeugen und wirksamen Arbeitern und Arbeiterinnen Gottes verwandeln? Heutzutage scheint besonders der Umgang mit der eigenen Freiheit für jungen Menschen die Herausforderung schlechthin zu sein. Wie verhalten sich persönliche Freiheit und eheliche Bindung zueinander? Die Angst, das $J a$-Wort zueinander zu sagen, sich ganz für den Anderen oder Gott zu entscheiden wird durch die im Hintergrund dieser Entscheidung stehende Herausforderung sichtbar. Hier wird eine unvermeidbare Wandlung der eigenen Person, des eigenen Ichs, des eigenen Charakters und der persönlichen Gewohnheiten verlangt und letztlich auch die bewusste und ernst gemeinte Übernahme von Verantwortung. Diese Wandlung und Entscheidung für den Anderen aber steht im eklatanten Widerspruch zum allseits gelebten und gepriesenen Individualismus einer geradezu hedonistischen Selbstverwirklichung.

\section{Die eheliche Kirchlichkeit}

Wenn es sich tatsächlich um eine authentisch christliche Ehe- und Familienspiritualität handeln soll, dann darf diese nicht ohne das kirchliche Leben zurechtkommen wollen, sondern muss in ihrer Klugheit aus der reichen theologischen und spirituellen Tradition schöpfen. Knieps-Port le Roi will in der Kirchlichkeit eine wichtige Bedingung sehen, die das eheliche Leben auf die spirituelle Relevanz hin überprüfen kann. Jede Beziehung, die christlich leben will, braucht unter anderem auch einen Kontext, eine Geschichte, eine Tradition und religiöse Ausdruckformen, sonst bleiben ihr die religiösen Dimensionen dieser Rahmenbedingung einfach verschlossen ${ }^{76}$ : „Ein solches Repertoire stellt die

\footnotetext{
${ }^{75}$ Ebd., S. 261.

${ }^{76}$ Ebd.
} 
kirchliche Überlieferungsgemeinschaft mit den biblischen Erzählungen sowie ihrer reichen Glaubenslehre und Praxis bereit und es kommt darauf an, diesen Fundus als Erschließungsbasis, Gestaltungsprinzip und kritisches Korrektiv für den menschlichen Erfahrungsraum ehelicher Beziehung einzusetzen. Andernfalls kann es leicht geschehen, dass wir uns eine eheliche Spiritualität nach unseren eigenen Wünschen und Vorstellungen zurechtlegen, die aber nicht den Namen «christlich» verdient und in der wir unseren eigenen Götzen, nicht aber dem lebendigen Gott begegnen“".

Für ein Ehepaar, das den Weg der christlichen Spiritualität bewusst und gemeinsam aufschlagen will, werden dann die kirchlichen Angebote und auch die kirchliche Lehre kein Hindernis oder Hemmnis mehr sein, sondern werden als eine große Hilfe und Ermöglichung des vertieften Weges angesehen und verstanden werden. Das ganze sakramentale Leben mit all seinen Dimensionen eröffnet dann dem Ehepaar einen direkten Zugang zur communio mit Gott, der Kirche und den Mitmenschen, die sich auf dem gleichen Weg befinden. Mit der positiv gelebten Kirchlichkeit überschreiten die Ehepartner und Familien so die Schwelle einer im Vergleich mit Anderen bloß außergewöhnlichen, weil objektiven, prüfbaren spirituellen Entwicklung und Entfaltung, um das endgültige Ziel - die Heiligkeit zu erreichen ${ }^{77}$.

\section{Die eheliche „Andacht"“}

Um die religiösen, ja spirituellen Dimensionen der menschlichen - ehelichen Beziehungen zu erschließen, bedarf man eines besonderen hermeneutischen Schlüssels. Anhand der kirchlich-theologischen Tradition und Reflexion, der zahlreichen biblischen und historischen Beispiele könnte man beobachten, wie andere Menschen, Ehepaare und Familien diese spirituelle Lebensart auf ihren Erfahrungsraum angewandt und welche Ergebnisse sie dabei erzielt haben. Knieps-Port le Roi sieht diese Aufgabe als die erste Handlung auf dem Weg der Suche und Erkundung der Art und Weise, wie, wo und wann in den Partnerbeziehungen jener tiefere - spirituelle Sinn aufscheint, in dem Gott selbst wirkt und die Ehepartner Gott in ihrer Beziehung auch wirken lassen ${ }^{78}$.

${ }^{77}$ Z. Nosowski, Parami do nieba. Matżeńska droga do świętości (dt.: Gemeinsam in den Himmel. Der eheliche Weg zur Heiligkeit), Warszawa 2004, S. 1-262. Das Buch beschreibt und analysiert 83 Ehepaare aus der Geschichte der Katholischen Kirche, die bereits zur Ehre der Altäre erhoben wurden.

${ }^{78}$ K. Knieps-Port le Roi, Ehespiritualität..., op. cit., S. 261. 
Es handelt sich also um die grundsätzliche Bereitschaft der Ehepartner, die sie zu einem aufgeschlossenen Gemeinschaftsleben befähigt, in dem beide Partner das alltägliche Verlangen nach Gott, nach einer lebhaften Beziehung mit ihm, nach seinem göttlichen Wirken in ihrem Leben offenkundig manifestieren. Diese besondere Bereitschaft überwindet die menschlichen Ängste vor dem „Ungewissen“, vor dem, was eine göttliche Beziehung mit sich bringen könnte. Sie „löscht“" alle Befürchtungen vor der Zukunft, vor eventuellen Veränderungen des selbst geplanten und organisierten Lebens. Diese Bereitschaft muss auch eine Frucht der wahren Freiheit sein, in welcher die Ehepartner sich selbst und ihre Beziehung aus freien Stücken dem Wirken Gottes übergeben und sich auf ihn einlassen. Diese Bereitschaft der Ehepartner stellt letztendlich eine Gott gegebene Einwilligung dar, die es diesem erlaubt, in ihre Beziehung einzugreifen, ihnen Impulse und Anregungen zu geben, damit sie ihr Eheleben im göttlichen Sinne gestalten können.

Diese spirituelle Bereitschaft identifiziert Knieps-Port le Roi als besondere Aufmerksamkeit und Achtsamkeit oder sogar Empfindsamkeit der Ehepartner für die Gegenwart Gottes und nennt sie nach der kirchlichen Tradition „Andacht" oder „Andächtigkeit"“79. Für den Autor ist es unabdingbar, dass die Ehepaare und Familien, die sich auf den authentischen Weg der Spiritualität begeben, sich auch fähig machen, ,den Beziehungsalltag zu unterbrechen, um sich auf diese Weise seiner spirituellen Tiefdimensionen zu vergewissern" ${ }^{\text {“80. }}$. Dabei weist Knieps-Port le Roi auf drei Komponenten der ehelichen und familiären Gemeinschaft hin, die bei einer effizienten Entwicklung ihrer Alltagsspiritualität behilflich werden können:

- Zeitlichkeit. Christliche Spiritualität bindet sich traditionellerweise an eine Reihe von Festzeiten an, die aus dem Alltag hervortreten und ihn unterbrechen. Sinn und Zweck der ehelichen Andacht sollte es deshalb sein, den gleichförmigen Fluss der Zeit zu unterbrechen und sich in besonderen Momenten des gemeinsamen Lebensweges zu versichern. Die gute Gelegenheit und der rechte Augenblick wird im Neuen Testament als kairos bezeichnet; es ist dem biblischen Zeugnis zufolge auch immer jener Zeitpunkt, an dem die vergehende Zeit auf die Geschichte Gottes mit den Menschen hin transparent wird, also auch darauf, wie Gott in die Beziehungsgeschichte zweier Partner hineinspielt.

- Räumlichkeit. Traditionelle Spiritualität bedient sich neben besonderen Zeiten auch besonderer Räume. Das Kloster, die Kirche und das Heiligtum

\footnotetext{
${ }^{79}$ Ebd., S. 262.

${ }^{80}$ Ebd.
} 
sind klassische Stätten für die Andacht und Begegnung mit Gott. Der eheliche (und familiäre) Raum schlechthin ist nun aber einmal das Zuhause, also jener Platz, an dem sich das Leben in all seinen - auch nicht so frommen - Dimensionen abspielt. Das II. Vaticanum hat diesem Raum einen ekklesiologischen Rang verliehen und ihn als „Hauskirche“ bezeichnet. Es geht jedenfalls nicht darum, einen eigenen Gebetsraum einzurichten, weil ja der ehelich-familiäre Lebensraum bereits selbst als Gottesdienstraum begriffen werden soll. Es wäre aber durchaus sinnvoll, einen bestimmten Platz inmitten des gewohnten Lebensraumes auszuweisen, an dem sich die Ehegatten einander begegnen und eine tiefere Dimension in diesen Lebensraum und dadurch auch in ihre Beziehung eindringen lassen (Symbole und Rituale). Im Beziehungsalltag bedienen Ehepaare sich oftmals bestimmter Zeichen und Rituale, die auf den Grund ihres Zusammenseins in der einander geschenkten Liebe verweisen. In diesem Kontext nennt Knieps-Port le Roi ganz konkret den „Kuss und die Umarmung bei Abschied und Wiedersehen, das gemeinsam eingenommene Mahl, aber auch die geteilte Erinnerung an eine Reise oder an gemeinsam gemeisterte schwierige Lebenssituationen; diese sind ja, falls sie nicht zu leeren Floskeln oder inhaltslosen Nettigkeiten verkommen sind, nicht nur Relikte eines vergangenen Liebesglücks, sondern bewahren etwas von dem Glanz dieser Liebe und setzen es gegenwärtig“"81.

Diese symbolischen Handlungen tragen etwas Metaphysisches in den monotonen Alltag hinein. Als Zeichen der gegenseitigen bräutlichen Liebe ähneln sie den Sakramenten und Riten der offiziellen Religion. Diese häusliche „Liturgie" lässt die Ehegatten und Familien aus der göttlichen Quelle schöpfen, den Glauben festigen und mutig in die eschatologische Zukunft schauen. Diese beginnt allerdings bereits in der eigenen humanökologischen Umwelt der Eheleute und der Familie.

\section{Fr Artur Żuk: Selected aspects of the spirituality of the marriage and families prepared next time as the form of the word of the permanence of spiritual values for the society}

The article constitutes the attempt to show forms directed next time theological and checked in the pastoral work of the spirituality of the marriage and families in the meaning of new evangelization. The permanence of spiritual values of the Christian marriage and the family is based on a bond consciously and actively survived of persons, which is very important for society. A perso-

\footnotetext{
${ }^{81}$ Ebd.
} 
nal decision of spouses constitutes the base of this Christian spirituality informed next time confirmed with voluntary sacramental word "yes".

Key words: the spirituality of the marriage and families, spiritual values, new evangelization. 